\title{
Pierre Bréchon, Bruno Duriez, Jacques Ion (éds.), Religion et action dans l'espace public
}

Paris, L'Harmattan, 2000, 301 p. (coll. « Logiques politiques »)

\section{Pauline Côté}

\section{(QpenEdition}

\section{Journals}

Édition électronique

URL : http://journals.openedition.org/assr/423

DOI : $10.4000 /$ assr. 423

ISSN : $1777-5825$

\section{Éditeur}

Éditions de l'EHESS

\section{Édition imprimée}

Date de publication : 2 octobre 2001

Pagination : 93-156

ISBN : 2-222-96712-0

ISSN : 0335-5985

\section{Référence électronique}

Pauline Côté, «Pierre Bréchon, Bruno Duriez, Jacques Ion (éds.), Religion et action dans l'espace public

", Archives de sciences sociales des religions [En ligne], 116 | octobre - décembre 2001, document

116.7, mis en ligne le 21 novembre 2005, consulté le 24 septembre 2020. URL : http://

journals.openedition.org/assr/423 ; DOI : https://doi.org/10.4000/assr.423 
84.95]). Attendu avec impatience, celui-ci ne nous déçoit pas.

Régine Azria.

116.7

BRÉCHON (Pierre), DURIEZ (Bruno), ION (Jacques), éds.

Religion et action dans l'espace public. Paris, L'Harmattan, 2000, 301 p. (coll. «Logiques politiques »).

L'heure est au transdisciplinaire et à la réciprocité des perspectives. Le phénomène religieux s'y prête merveilleusement et on ne peut que se réjouir de la publication de ce collectif, issu d'un colloque conjoint organisé en février 1999 par l'Association française de sciences sociales des religions et l'Association française de science politique. Chose rare pour ce genre d'ouvrage, une réelle logique d'ensemble se dégage autour de la problématique classique esquissée en introduction par B.D. Quelle est la permanence et la force du lien, direct ou indirect, entre religion et action publique ? Selon les auteurs, la question générale est abordée dans une perspective institutionnelle ou individuelle. Quelles stratégies de retrait, d'attestation ou de contestation du monde les groupements religieux promeuvent-ils? Quels liens, s'il en est, peut-on établir entre identité religieuse et engagement public ? Comment, en fonction de leur ethos religieux, les individus mettent-ils en œuvre une façon particulière d'être au monde (p. 17) ?

Sur ce canevas sont ensuite développés cinq motifs : les attitudes à l'égard du monde, les stratégies de visibilité ou de discrétion en catholicisme, la visibilité ou la discrétion des religions minoritaires, la pluralité religieuse et les formes d'implication sociale, les frontières $\mathrm{du}$ religieux. Pas moins de dix-sept auteurs brossent le tableau. La majorité des contributions privilégient une dimension ou l'autre de l'action institutionnelle catholique, ou du catholicisme. C'est le cas de J.-M. Donegani et de V. Tournier sur l'identité et la socialisation, de D. Andolfatto sur le rapport entre religion et implication syndicale ( CFDT, CGC, CFTC), de N. Viet-Depaule sur les prêtres ouvriers, de K. Talin et de P.-A. Turcotte sur la différence de culture politique des ordres religieux en France et au Québec, de C. Pina sur l'épiscopat français, d'É. Belouet et de J. Morlet sur l'action catholique, enfin, de D. Pelletier sur la carrière institutionnelle de l'idée de mission depuis la Révolution française.
L'équilibre de la composition est préservé par le traitement des stratégies religieuses minoritaires de visibilité ou de discrétion dans l'espace public, que ces minorités soient anciennes ou récentes. $\mathrm{P}$. Birnbaum rappelle le cas des juifs d'État, S. Trudel fait état de celui du judaïsme sarcellois alors que G. Vincent traite des associations protestantes d'entraide. J. Césari discute, par ailleurs, de l'intégration socio-politique des musulmans français et $\mathrm{R}$. Dericquebourg, du rapport au monde de trois minorités religieuses contemporaines: les Témoins de Jéhovah, La Famille et le Raëlisme.

Au fil de l'ouvrage, le découpage de l'objet et la portée de l'interprétation se révèlent une préoccupation constante. Ainsi, C. Dubar plaide pour une définition extensive du religieux, englobant les croyances subjectives, en même temps qu'il insiste sur les transactions identitaires dans le champ professionnel. A. Micoud, considérant le religieux comme construction symbolique qui engage un nouvel être au monde, peut ainsi voir dans l'écologisme une nouvelle religion civile. J. Ion, par ailleurs, revisite les modes d'engagement dans l'espace public - publicisation et personnalisation dont on conçoit qu'ils puissent être appliqués à certaines revendications religieuses actuelles immédiatement perçues comme envahissement ou reconquête. À ce sujet, le souci d'ancrage empirique produit d'heureux résultats. Par le biais de l'élaboration du rapport Dagens, Christine Pina montre l'apprentissage laborieux de la consultation de la part d'une Église dépeuplée, en position de repli. De même, il faut signaler la finesse de l'analyse faite par Jocelyne Césari des déclinaisons socio-politiques de la référence musulmane qui, même dans l'intégralisme, peut prendre la forme soit d'un piétisme personnel, soit de l'associationnisme civil, soit de l'action civique (lutte anti-racisme), soit, encore, de la protestation radicale. Il est aussi évident à la lecture de Césari, comme à celle de Birnbaum, que la visibilité ou la discrétion ne se présentent pas nécessairement comme des options dans la mesure où il $\mathrm{y}$ a relégation institutionnelle et stigmatisation.

Pour conclure, Pierre Bréchon n'hésite pas à pousser plus avant la réflexion. La question du lien entre identité religieuse et politique a-telle encore un sens au constat d'identités religieuses flottantes, ou de la formation d'une identité areligieuse, voire même antireligieuse? L'espace public est-il co-extensif à l'espace politique partisan et aux idéologies? Le statut des religions se transforme dans l'espace public, la laïcité est dépassée comme cadrage et fonctionne de manière différente, 
comme lorsqu'elle départage les groupes religieux dignes de temps d'antenne des autres (288). Ici, on peut regretter que la question de la sectorisation du religieux, comme celle de la lutte pour le classement auprès des autorités publiques, ne soient pas abordées.

Cet ouvrage remet avec profit les notions de champ religieux et d'espace public sur le métier. L'ouverture de nouveaux chantiers pour les politistes et les sociologues de la religion pourrait également exiger, dans l'avenir, que l'on s'interroge à nouveau sur les limites même du phénomène religieux. Cela pourrait impliquer de situer la notion en rapport avec la morale et la spiritualité d'une part, la magie d'autre part, y compris sous leurs formes nouvelles et alternatives. Que croient et que pratiquent, par exemple, les militants radicaux et anarchistes contre la mondialisation? Quelle religion des droits de l'homme se dessine? ( J. Spickard) Quels seront ses rapports avec les religions instituées et les idéologies?

Le collectif rassemblé par P.B., B.D. et J.I. comble également une lacune. Ces dernières années, d'autres livres, la plupart anglo-saxons, ont illustré une convergence semblable des domaines autour de l'objet religieux. On pense entre autres à Sacred Companies: Organizational Aspects of Religion and Religious Aspects of Organizations. L'ampleur des matières traitées, le souci empirique, les ouvertures pratiquées en conclusion font en sorte que Religion et action dans l'espace public contribue à redynamiser la sociologie politique du religieux. Malgré tout, il reste tributaire de son objet, à savoir le modèle confessionnel de gestion du pluralisme religieux. À lire avec La religion en miettes ou la question des sectes (Danièle Hervieu-Léger, Paris, Calmann-Lévy, 2001, 222 p. [coll. "Essai Société »]) et Les métamorphoses de la régulation politique (Jacques Commailles, Bruno Jobert, éds, Paris, LGDJ, 1999, 381 p. [coll. «Droit et société » 24]).

Pauline Côté.

\section{8}

BUJARD (Marianne).

Le Sacrifice au Ciel dans la Chine ancienne. Théorie et pratique sous les Han occidentaux. Paris, École française d'Extrême-Orient, 2000, 261 p., (préface de Kristofer Schipper), (cartes, illustr., index), (coll. «Monographies », 187).

Une déconstruction bien argumentée est toujours savoureuse, surtout lorsqu'elle touche aux idées les mieux établies dans l'inconscient de toute personne cultivée, ainsi celles concer- nant la Chine et qui plus est le culte impérial. Les auteurs chinois en sont convaincus et les grands maîtres des études sinologiques occidentales, tel Henri Maspero, disent de même : le symbole du lien que l'Empereur ménage entre l'humanité et le Ciel dispensateur de tout bienfait serait, depuis la plus haute Antiquité, le sacrifice jiao qu'il fait dans la banlieue sud de la capitale. La surprise est grande de découvrir une réalité différente de ce qui est enseigné depuis deux millénaires. Pour nous convaincre de l'incroyable, l'auteur procède avec sûreté, appuyant son argumentation sur des traductions nombreuses de textes inconnus jusqu'alors en langues occidentales. De fait, il apparaît certain que ce fameux sacrifice jiao a été une invention, créée de toutes pièces par les lettrés de la cour des Han occidentaux (ou antérieurs), au II ${ }^{\mathrm{e}}$ siècle avant notre ère, et systématisée dans son Chunqiu fanlu par le penseur Dong Zhongshu (195-115 av. J.C.), l'un des artisans principaux de ce qu'il faut appeler la métamorphose du confucianisme. Les textes antiques dont se targue Dong Zhongshu ne disent pas ce qu'il leur fait dire : le concept de jiao, dans ses mentions les plus anciennes, connote l'idée d'un espace situé aux limites de la ville, non pas d'un sacrifice, et surtout pas d'un sacrifice au Ciel ; car les sacrifices réservés à la maison royale à l'époque pré-impériale étaient essentiellement un culte aux ancêtres. Sous les premiers empereurs - Qin puis Han - les sacrifices jiao étaient multiples par leur localisation et par leurs agents, destinés en dernier ressort à obtenir l'immortalité du souverain. L'action de Dong Zhongshu et de ses pairs va être double : d'une part, ils veulent ériger en culte suprême le rituel qu'accomplira l'empereur lorsque, en personne, il sacrifiera un bœuf pour communiquer avec son père, le Ciel, et connaître la volonté de celui-ci, et ils travaillent à en faire la base d'une nouvelle religion d'État; d'autre part, ils s'emploient à éliminer les cultes locaux (leur cartographie pp. 241-246) et, par la même occasion, leurs acteurs, les magiciens fangshi, leurs grands rivaux. Dong Zhongshu tenta d'entraîner l'adhésion de l'empereur $\mathrm{Wu}$ des Han (r. 144-87); mais le premier sacrifice impérial dans la banlieue sud de la capitale fut réalisé en 31 avant notre ère seulement, par l'empereur Cheng (r. 32-7), et encore ne s'adressait-il pas au Ciel mais au « Grand Un » Taiyi, dont le culte était en partie géré par les fangshi..

Sur ce fond d'histoire qui devient évidence grâce au traitement des textes présentés par l'A., une vaste fresque se dessine, qui explique les innombrables indécisions dans la politique religieuse officielle, jusqu'à l'époque commu- 